\title{
Involvement of Patients' Families in Care of Critically III Patients at Kenyatta National Hospital Critical Care Units
}

\author{
Pauline Muthoni Maina*, Samuel Kimani, Blasio Omuga \\ School of Nursing Sciences, University of Nairobi, Nairobi, Kenya \\ Email address: \\ muthonipauline015@gmail.com (P. M. Maina), tkimani@uonbi.ac.ke (S. Kimani), mitenga@yahoo.com (B. Omuga) \\ ${ }^{*}$ Corresponding author
}

\section{To cite this article:}

Pauline Muthoni Maina, Samuel Kimani, Blasio Omuga. Involvement of Patients' Families in Care of Critically Ill Patients at Kenyatta National Hospital Critical Care Units. American Journal of Nursing Science. Vol. 7, No. 1, 2018, pp. 31-38.

doi: 10.11648/j.ajns.20180701.14

Received: October 28, 2017; Accepted: December 9, 2017; Published: January 19, 2018

\begin{abstract}
Patients assess the likely benefits and risks of a recommended treatment or investigation and make a decision to either accept or refuse treatment. When a patient loses the capacity to participate meaningfully in decision making, a means should exist to ensure decisions that represent the patient's goals, preferences, and interests are made. This means is substitute decision making, and it usually occurs when a spouse, partner, close family member, or friend assumes this responsibility on behalf of the incapacitated patient. Limited involvement in patient care activities at the hospital can lead to distress in the family as well as challenge family members in assuming the likely expected role when the patient returns home. This study aimed at determining the nature and extent of family/substitute decision makers' involvement in care of the critically ill patients, guiding policies and the perspectives of nurse managers on involvement in Kenyatta National Hospital (KNH) critical care units (CCUs). This was a descriptive cross sectional study with family members and CCU nurse managers as the study participants. Key informants' interviews and in depth interviews were conducted. The sample size was 52 family members and four nurse managers. Quantitative data was analyzed using Statistical Package for Social Sciences (SPSS) version 21.0 and descriptive content analysis for qualitative data. Family members reported emotional distressed from the admission of a family member to the critical care unit. However their level of satisfaction with the extent of involvement was above average at a mean of 6.5. The activity mostly involved in was sharing of general information at $57.7 \%(n=30)$ with $36.5 \%(n=19)$ feeling they should have been provided with in depth information regarding the patients care. The key themes from interviews with family members were: limited information involvement, guilt feeling, and appreciation. Nurse Managers reported KNH has a closed visiting policy with none feeling it should be changed to an open policy. They also unanimously agreed that family members should be involved in care of the critically ill patients through information sharing and counseling. Two nurse managers felt primary care nurses should involve families in general nursing activities such as oral care with all agreeing that the nurses don't involve families in these activities. There was a statistical relationship $\left(\mathrm{p}<0.05\right.$ at a $95 \%$ confidence interval and $\left.\mathrm{R}^{2}=0.689\right)$ between the perspectives of nurse managers and the nature and extent of involvement of family members in care.
\end{abstract}

Keywords: Involvement of Family Members, Critically Ill Patients' Care, Critical Care Unit, Substitute Decision Makers, Kenyatta National Hospital

\section{Introduction}

\subsection{Background Information}

Patients weigh the likely benefits and risks of a proposed procedure or management and make a decision to either accept or reject the proposed recommendations. When a patient loses the capacity to participate meaningfully in decision making, a means should exist to ensure decisions that represent the patient's goals, preferences, and interests are made. This means is substitute decision making, and it usually occurs when a spouse, partner, close family member, or friend assumes this responsibility on behalf of the incapacitated patient [1]. Acknowledgement of family as an interrelated system signifies a change from the disease-centred practice to a practice that holistically embraces patients, family members and their way 
of life into care [2, 3]. Families of critically ill patients often have needs which they expect the health care providers to assist them meet. These needs can be broadly categorized as: need to know, need for information that is consistent, need to be involved in care, and need to make sense of what is being experienced $[4,5,6,7]$.

A study conducted by Ngui in 2006 on the needs of families in $\mathrm{KNH}$ intensive care units identified the following ten needs in order of priority as their most necessary needs to be met: 1 . To have assurance that good care is being given, 2 . To have good communication with health care team, 3. To feel that the staff are caring, 4. To get questions addressed truthfully, 5. To be given specific elements on the patient's progress, 6. To be supported with sensible hope, 7. To feel welcome and accepted by care providers in the hospital, 8 . To be given explanations in understandable terms, 9. To know possible outcome and 10. To be provided with information about the patient every day [9]. Families of patients in the KNH ICU are able to identify their needs, but these needs are not adequately met [9].

In critical care units family needs can only be met through involvement. Involvement can range from simply presence to active involvement such as receiving care and information while being actively involved in the patient's care and decision making [8]. A review of 124 global studies on patient and family involvement in adult critical and intensive care settings done by Kitto et al., (2015) did not identify any African study on this topic making it unknown.

\subsection{Statement of the Problem}

In Kenya most of the admissions to critical care units are as a result of surgeries (30\%), trauma (26\%) and cardiac diseases $(15 \%)$ [10]. These diseases have been on the rise resulting to an increase in the number of patients requiring admission to CCU specifically in $\mathrm{KNH}$ as it is the main referral hospital in the country.

Patients who require critical care following trauma or cardiac diseases are many a time unable to participate in treatment and decisions regarding their care and may recover with variable levels of disability. This makes them require rehabilitation and increasing dependency on others at home after discharge from hospitals. Close family members are requested to decide with the best interest of the patient on the preferred treatment and are often tasked with the responsibility of caring for their relative during post rehabilitation period at home.

There is limited critical care literature on patient and family-centred model of delivering care while the studies conducted in this area indicate a dissatisfaction of family members in the nature and extent of involvement in the patients' care [3]. Restricted involvement in patient care activities becomes challenging to close family members when assuming the expected roles when the family member returns home [11]. Although there is little literature on involvement of family members in Kenya, primary care nurses in KNH CCUs include a component of family in the care plans but little is documented on what care families receive or to what extent they are involved in the care.

\subsection{Justification}

In Kenya public critical care units have $100 \%$ bed occupancy throughout the year. The leading causes of admission to $\mathrm{KNH}$ critical care units which is the main referral hospital in Kenya are mainly surgeries, followed by trauma resulting from road traffic accident and finally cardiac diseases. Patients' families are often tasked with the responsibility of caring for their relative during post rehabilitation period at home. The support from family is viewed as critical in achieving desirable patient outcomes and the quality of medical care $[12,19]$.

Majority of the reviewed studies showed dissatisfaction of families in the extent to which they were involved in care. No regional or local study was available for review on this specific topic despite a previous study identifying that the families of patients in KNH have needs that were poorly met [9]. The purpose of this study was to establish whether patients' families get involved in the care of critically ill patients in Kenyatta National Hospital get involved in care, policies that guide the involvement and the perspectives of the CCU nurse managers on this concept.

\subsection{Objectives}

The broad objective was to determine families' involvement in the provision of care to critically ill patients in Kenyatta National Hospital critical care units.

Specific objectives

1. To determine the involvement experiences of patients' families in regard to the nature and extent of their involvement in critically ill patients care.

2. To explore the perspectives of nurse managers towards involvement of families in the care of critically ill patients.

3. To describe the policies guiding the involvement of families in care of critically ill patients.

\section{Literature Review}

\subsection{Visitation Policies}

The critical care unit's policy on the visitation hours sets the rules of engagement between parties and can have notable effect on the outcome of the patient and family satisfaction [13]. Majority of findings of a review of 22 studies on visiting policies in intensive care units conducted [14] in Iran showed the open ICU visiting strategy is essential for the patients and their families. Even though studies have demonstrated positive physiological and comforting effects of family visits to critically ill patients, studies conducted in United Kingdom in 206 hospitals, the United States of America in 606 hospitals and also in Dutch ICUs showed majority had restricted visiting policies $[3,15$, 26]. These findings are disturbing considering that studies done earlier had already indicated that an open visiting policy doesn't have negative effects on the patient. 


\subsection{Involvement Policies}

Studies conducted in Bahrain and Malawi showed that there were no policies on involvement and nurses expressed a need for a clear policy outlining the extent to which family members' can get involved in the care, the limitations during family visits and participation in care as well as guiding policies on providing support to ICU patients' family members $[11,18]$. Although a study in four ICUs in South Africa showed there were policies to guide involvement, some nurses would determine what to share depending on what they were willing or not willing to discuss with families. [19]. This indicates that regardless of the guiding policies, nurses' perspectives play a great role in the nature and extent of involvement of patients' relatives in the care of the critically ill patient.

\subsection{Perspectives of Nurses on Involvement of Family in Care of Critically Ill Patients}

\subsubsection{Nurses Perspectives of Roles to Relatives}

A study conducted by Omari, (2012) on nurses' perceptions of their roles toward the families of hospitalized critically ill patients at four hospitals in Jordan reported high levels of family involvement. $127 \mathrm{CCU}$ nurse respondents reported having performed interventions to family members that enhanced family involvement. It may be concluded that the interventions that nurses performed are what they perceive to be their roles towards families whereas those not performed are not seen as the nurses' roles [8].

\subsubsection{Nurses Perspectives on Involvement of Family in Care}

A study in Bahrain on family members' involvement in the care of critically ill patients in two intensive care units found that nurses were hesitant in involving family in care even though family members showed general willingness to participate in care and instead expressed a need for policy guidelines on the extent to which family members' can get involved, family limitations during visits and participation in care [11].

The factors that nurses considered before involving family in care as well as reasons for hesitance in including families in care despite acknowledging the benefits include: previous unpleasant experience, busy schedule, the patients' clinical condition and treatment being given, privacy and safety concerns, physician orders on how much information to provide to relatives type of caring activity, family relationships, lack of adequate ICU training and feelings of inadequacy, lack of skills in care and respect of nurses' role by family members, emotional responses, nurses discomfort and stress from constant observation by the visiting family communication challenges, culture and religion, distrusting relatives, fear of blame if something goes wrong and lack of guiding policies on how to manage relatives $[11,18,19,20]$.

\subsection{Involvement Experiences of Family Members in Critical Care Units}

While the traditional, clinician-centered approach to critical care has limited family involvement, patient- and family centered care (PFCC) allows families to take an active role with an intent of bringing wholeness to the patient by ensuring collaboration and personalized care that respects the values, beliefs, and experiences of the individual [13, 14, 21, 22, 29].

In a study done by Fateel et al., (2015) on family members' involvement in the care of critically ill patients in Bahrain, participants expressed their desire to be near the critically ill family member. However most of the study respondents reported that they were ignored, handled as if they did not exist and felt that nurses failed to be honest in answering questions on the patient's condition. They concluded that most nurses feared disclosing information on the patient's condition and hesitated revealing if the patient's condition had deteriorated [11]. These sentiments concur with those made by participants in studies conducted in Canada and Georgia who felt that they had to be in good terms with the nurses so as to be involved else they were ignored and not allowed to participate in the patients care. Family members viewed the wall between the waiting bay and the ICU as a barrier to being with their family member. This wall was what they had to breach to gain access to their ill relative, the nurses and the physicians [6, 11, 25, 28]. Family members appreciated being involved as evidenced by a study conducted in Australia by Chaboyer et al, (2010) where those who participated in care showed high level of satisfaction. Similar sentiments were also expressed by participants who were involved in care in the Fateel et al., (2015) study. These participants reported that providing care to the critically ill family member helped in maintaining family bonds and cohesiveness while minimizing family unit disturbance resulting from a family member's admission to the ICU. They saw it as a stepping stone in assisting the patient be able to resume their normal life when discharged. Families expressed gratitude to nurses who understood and acknowledged what they were experiencing and those who took the time to provide honest, accurate information about their loved one $[6,11,27]$.

\section{Methodology}

This study was a descriptive cross-sectional study. Qualitative data was collected using in depth interviews from family members while quantitative data was derived from specific responses made to the interview questions in the key informant interview and the in depth interviews. This study was conducted in Kenyatta National hospital (KNH) critical care units (CCUs) which include main ICU with a 21 bed capacity and medical ICU with a bed capacity of five. It is located approximately 1.5 kilometers from Nairobi Central Business District in Nairobi County, Kenya, East Africa. It is the largest referral hospital in East Africa and the second largest in Africa with a bed capacity of 1900.

The study population was family members/ substituted decision makers of adult patients in the CCUs and nurse managers in charge of main and medical CCUs as key informants. The sample size for family members was 
determined using the formula by Fisher's et al (1998) formula, $52 \mathrm{~s}$ family members one for each adult patient admitted in the CCUs during the study period while purposive sampling was done for the four Key Informant Interview (KII) respondents. The researcher submitted the study proposal for ethical approval to conduct the study from the Kenyatta National Hospital and University of Nairobi Ethics and Research Committee (KNH/UON-ERC) and the Kenyatta National Hospital Administration. Participation in the study was voluntary and written informed consent was obtained from all study participants.

Data was collected using a key informant interview guide with the nurse mangers in charge of critical care units while an in depth interview guide was used to collect data from the family members. Univariate analysis was used for descriptive analysis of the nurse managers' perspectives on involvement policies and bivariate analysis for the relationship between the nature and extent of involvement of family members in care of critically ill patients in Kenyatta National Hospital critical care unit and the perspectives of nurse managers on the involvement concept using SPSS version 21.0.

\section{Results}

\subsection{To Determine the Involvement Experiences of Families in Regard to the Nature and Extent of Their Involvement in Critically Ill Patients}

\subsubsection{Respondents Demographic Data}

The respondents were aged 30-39 40\% ( $n=21)$, followed by $50-5930 \% \quad(n=16)$, while $40-49$ made $14 \% \quad(n=7)$. Respondents below 30 years were $12 \%(n=6)$, and above 60 year were, $4 \%(n=2)$. There were more males at $53.8 \%)$ $(n=28)$ than females $46.2 \%(n=24)$ involved in the study.

\subsubsection{Activities Family Members Were Involved in}

The activity majority of the respondents were involved in was acquiring general information, $57.7 \% \quad(n=30)$ followed by consenting for surgical procedures $46.2 \%(n=24)$ while the least was massaging the patient at $1.9 \%(\mathrm{n}=1)$. Male were involved in more activities than females. The correlation $(\mathrm{r}=0.082)$ shows that there is a positive but weak relationship between Gender and activities that respondents were involved in.

Table 1. Activities family members were involved in

\begin{tabular}{lll}
\hline Activities Involved in & Frequency & Percent \\
\hline Receiving general information & 30 & 57.7 \\
Consenting for surgical procedures & 24 & 46.2 \\
Buying medication & 15 & 28.8 \\
Blood donation & 12 & 23.1 \\
Payment of hospital bills & 10 & 19.2 \\
Presence during investigational procedures & 6 & 11.5 \\
Feeding the patient & 4 & 7.7 \\
Giving psychological support to patient & 4 & 7.7 \\
Oral care & 2 & 3.8 \\
Massaging patient & 1 & 1.9 \\
\hline
\end{tabular}

\subsubsection{Extent of Involvement and Level of Satisfaction}

Female were more satisfied at an average of (7) than male
(6) in the extent of involvement in the care of the critically ill patients'. The correlation $(\mathrm{r}=0.078)$ between gender of respondent and extent of involvement is positive but weak.

Table 2. Gender of respondents and extent of involvement.

\begin{tabular}{ll}
\hline Gender & $\begin{array}{l}\text { Average of Extent of involvement and } \\
\text { satisfaction level (1 lowest 10 highest) }\end{array}$ \\
\hline Female & 7 \\
Male & 6 \\
Mean & 6.5 \\
\hline
\end{tabular}

\subsubsection{Activities Wished to Be Involved in but Was Not}

Family members mostly wished to be involved in getting in-depth information on patient care $35.5 \%(n=19)$ followed by bathing and dressing the patient $13.5 \%(n=7)$ while the least wished was attending to elimination needs at $1.9 \%$ $(n=1)$ table $3.50 \%(n=26)$ of the respondents felt they were fully informed on the patient's condition, $32 \%(n=17)$ on the patient's prognosis and $42 \%(n=22)$ on the care the patient was receiving. The extent of knowledge for majority respondents' in the different aspects of treatment of the patients was alternated between partial and full involvement.

Table 3. Activities wished to be involved in but wasn't.

\begin{tabular}{lll}
\hline $\begin{array}{l}\text { Activities He/she Wished To be Involved in } \\
\text { but wasn't }\end{array}$ & Frequency & Percent \\
\hline In- depth information on patient care & 19 & 36.5 \\
None & 18 & 34.6 \\
Bathing and dressing the patient & 7 & 13.5 \\
Everything happening to the patient & 4 & 7.7 \\
Feeding the patient & 4 & 7.7 \\
Giving oral medication & 3 & 5.8 \\
Turning and massaging patient & 2 & 3.8 \\
Accompanying patient for procedures & 2 & 3.8 \\
Mouth care & 1 & 1.9 \\
Elimination needs & 1 & 1.9 \\
\hline
\end{tabular}

\subsubsection{Implications of Lack of Full Involvement}

When asked to state implications for their lack of full involvement in the different aspects of treatment for patients five reasons were given with lack of knowledge on how and when to contribute to patients care being the main one at (23.1\%, n=12), don't know how to care for patient once discharged $(21.2 \%, \mathrm{n}=11)$, inability to plan financially $(19.2 \%, \mathrm{n}=10)$, no $\operatorname{effect}(17.3 \%, \mathrm{n}=9$, emotional trauma $(9.6 \%, n=5)$ while $(9.6 \%, n=5)$ said they couldn't explain how they had been affected.

\subsubsection{Themes}

\section{(i) Limited Informational Involvement}

All participants expressed the experience of having a family member admitted in the critical care unit as emotionally distressing. Respondent three described the experience as an emotional burden that was hard to deal with while the fifth respondent reported poor concentration at work and reduced productivity due to the disturbing feeling of having the family member admitted in the critical care unit

Only a few of the respondents felt they fully knew the diagnosis, prognosis and care their critically ill patient was 
receiving. Majority were partially informed and felt they were only provided with the general information regarding the patient care and prognosis while in-depth details were left out. Families reported this as a key barrier to providing adequate care to their family member both in the hospital and at home upon discharge. Respondent one said beyond knowing the son got an accident and got injured in his head she barely knew where in the head what specific management he was receiving and what the possible outcomes of her son were while respondent three said she was only provided with the general information on the state of the patient but not specific details.

All respondents reported to be involved only when they visit the patient but not through other means such as phone calls etc. Respondent eight said I usually visit my husband every day but am only told about his progress twice a week. I know very little about the patient condition care or progress. Respondent 16 a mother with a son in the main ICU said $I$ heard the doctor say my son needs a lot of physiotherapy but since no one ever tells me if it was done, I usually massage his legs every time I visit him.

Families reported build up of anxiety levels due to what they termed as withholding of information by the nurses. Respondent 23 felt that he was being denied the only chance to participate in his son's care getting involved in activities such as bathing and turning is hard for me because it makes me emotionally vulnerable but I want to be involved in everything that is happening and being done to him through information and I feel am not getting that from the hospital. Respondent 40 said well I kind of understand why he is in ICU but I have no idea why he is on that machine (mechanical ventilation). No one has informed me about it. Providing us a daily report of what is happening to him is important because it will help us understand what is really happening, have trust in the nurses and some peace of mind.

Limited information sharing was noted as the key point for improvement for the nurses. Most family members felt that they should receive in-depth information from the primary care nurses caring for their patients rather than from the nurse managers or the nurse counselors as these gave them general information regarding the patient. Respondent 11 said nurses should give information about patient progress timely to enable us plan. At times we find the patient's condition has changed and this affects us emotionally and makes us depressed a lot.

\section{(ii) Guilt}

Family members reported feeling guilty about how minimally they were involved in the care of family members. They cited limited information provision as the key reason for the limited involvement as they did not know when to get involved and sometimes felt like they were neglecting their critically ill patients. Respondent three said I know very little about my patient condition because we aren't given much information on the patient. I don't know when or how to help or intervene when I visit which makes me feel guilty. Respondent 14 reported feeling bad and feels like he misses on the emotional support he could have provided to his patient due to lack of adequate information while respondent 17 felt it was hard to know exactly how to get involved in the care of the patient hence may give an impression of lack of support from the family yet that is not the case.

Respondent 21 said failure to be involved in the patient's care by the nurses gives an impression of neglect of the patient by us which makes me feel bad comments that were also made by respondent 24 . Respondent 28 also felt that failure of the hospital to involve him in the care of his patient made him feel less supportive of his patient.

\section{(iii) Appreciation}

Although majority of the respondent felt they were not fully involved in the care of their patients, they were quick to appreciate what nurses did for their patients.

Respondent 15 said it is impossible to compensate the nurses for the work they have done to my wife. I am grateful and I also pray for them. Respondent 31 and 32 felt they could not recommend anything for improvement but instead expressed their appreciation for the wonderful work and the dedication that the nurses showed towards their work. Respondent 33 said may God bless them abundantly for the good work they are doing while respondent 36 said even though my patient is not progressing well I know the nurses are trying their best. I can't complain.

\subsection{To Explore the Perspectives of Nurse Managers Towards Involvement of Families in the Care of Critically Ill Patients}

Two of the respondents have worked for more than 16 years in a critical care unit, one has worked for 13 years and the final one for 9 years. All the respondents agreed that indeed relatives should be involved in the care of critically ill patients. And they proposed three ways that they should be involved: through counseling, informing them on the progress and changes occurring to their patient and during care.

\subsubsection{Perspectives on Primary Care Nurses Roles and Involvement of Families in General Nursing Activities}

Three of the respondents agreed that primary care nurses have roles in the involvement of families in the care of patients and that they all perform their roles. They gave the following as would be roles of the nurses: updating and appraising relatives on changes that occur to patients and inform the doctor, reassuring relatives anxiety, answering their questions, informing them on buying drugs that are not available, coordination of payment for investigation that require payment prior to all the procedure and approaching the families to participate in care.

\subsubsection{Perspectives on Involvement in the General Nursing Activities}

Two of the respondents thought that families should be involved in the general nursing activities of patients in the CCU. The respondents who felt families should not be 
involved gave lack of knowledge and protection of patients' privacy as their reasons. All respondents unanimously agreed that primary care nurses do not involve families in general nursing activities of patients in the CCU and they gave the following as their reasons: nursing of critically ill patients is involving, nurses do not have knowledge and skills and lack of policies.

Respondents gave an average rate of involvement of family members of 6.25 with the highest being 8 and the least being 4 . They reported no feedback from nurses or families regarding their perspectives on involving family members in the care of the critically ill patients. Also no feedback has been received/ issued from family members regarding their experiences on the nature and extent to which they were involved in the care of critically ill patients in the unit.

\subsection{To Describe the Policies Guiding the Involvement of Families in Care of Critically Ill Patients}

According to the respondents there are no established policies that guide the involvement of families in critical care in KNH. Three of the respondents stated that there existed a standard guide for nurses on the nature and extent to which they can involve family members in care in $\mathrm{KNH}$ but they could not specifically mention it. Majority of the respondents $75 \%(n=3)$ agreed to the existence of a CCU visitation policy at KNH. They also unanimously agreed that it's not an open policy that allows relatives to visit any time. $66.7 \%(n=2)$ of those that agreed to the existence of the policy stated that it does not restrict who visits the patient.

Of the 3 respondents who agreed to the existence of a visitation policy, two stated there are no changes they would recommend in the current visitation policy. One proposed restriction of visitation to only the next of kin. There is a statistical relationship ( $\mathrm{p}<0.05$ at a $95 \%$ confidence interval and $\mathrm{R}^{2}=0.689$ ) between the perspectives of nurse managers and the nature and extent of involvement of family members in the care of the critically ill patients $\mathrm{KNH} \mathrm{CCU.}$

\section{Discussion}

\subsection{To Determine the Involvement Experiences of Families in Regard to the Nature and Extent of Their Involvement in Critically Ill Patients}

All family members described having unpleasant emotional experiences which affected their operations which were brought about by the admission of a family member to the critical care unit. This concurs with finding of Fateel et al, (2016) which reported disruption of the family system through admission of its member to a critical care unit that affected the tranquility of the family [11]. The key activity family members reported being involved in was receiving general information. The need for information was identified by as one of the key clusters of needs of family members [9]. This explains why the key activities family members identified as being involved in as general information sharing as it identified with their needs. It also explains why many felt the facility missed on in-depth information sharing. Nurses may be failing to give in depth information to families due to lack of interaction between families and primary care nurses and also due to fear of overburdening the family with detailed information.

The above average satisfaction levels on extent of involvement could be explained by the fact that most family members prioritized information sharing over active involvement in nursing activities as their key need. These findings are different from the finding of a study conducted by (Fateel, et al., 2015) in Bahrin were majority of the participants felt ignored and dealt with as if they did not exist while others felt nurses were not being honest on the patient's condition.

Families identified the key implications for their lack of full involvement in the different aspects of care for patients as lack of knowledge on how and when to contribute to patients care and Don't know how to care for patient once discharged while others felt guilty as they didn't know what to do to their patients. This concurs with sentiments made by participants in a previous study that providing care to the critically ill family member helped in maintaining family bonds and cohesiveness while minimizing family unit disturbance resulting from a family member's admission to the ICU. They also saw it as a stepping stone in assisting the patient be able to resume their normal life when discharged [11].

Like in previous studies respondents appreciated nurses who were caring for their patients and those who made an effort to involve them in care with most feeling the nurses effort went beyond what one would do for financial compensation. Kenyan public hospitals are transitioning from a period where a family member would be allowed to join the dependent family member at the hospital to assist in activities such as bathing and feeding the patient. Since critically ill patient have these services provided for by the critical care nurses the families feel the nurses are performing their roles too and feel the need to show gratitude $[6,11,27]$.

\subsection{To Explore the Perspectives of Nurse Managers Towards Involvement of Families in the Care of Critically Ill Patients}

All the nurse managers agreed that indeed relatives should be involved in the care of critically ill patients. However their idea of involvement is different from a study conducted in Bahrain by Fateel et al, 2015 where by nurses felt that families' knowledge on the patient would assist in personalizing care for the benefit of the patient rather than for the families' benefit. This contrast may be explained by the view of family members as victims of their patient suffering rather than as partners in the care of the patient by the nurse managers.

Majority of the nurse manager respondents agreed that primary care nurses have roles in the involvement of families in the care of patients admitted in the CCU in $\mathrm{KNH}$. Although the nurse manager felt that primary care nurses all 
perform roles to families, family members felt they were having limited interactions with the primary care nurses and made this a key recommendation for improvement. They felt more information came from nurse managers (ward in charges and nurse counselors) rather than the primary care nurses who they preferred join them at the bedside when they visited the patient to address their concerns. This may be due to the need by the family members to learn from the primary care nurse aspect of care that they can employ at home once the patient is discharged. This dissatisfaction is similar to previous studies where nurses were not readily available to attend to families needs [6, 11, 25, 28].

Apart from the patient's condition other factors that determine when and how often families get involved in provision of care for patients in $\mathrm{KNH}$ are different from those identified in other studies [11, 18, 19, 20].

This difference is due to the fact that in $\mathrm{KNH}$ it is the nurse managers and nurse counselors who interact with families unlike in these studies where primary care nurses interacted with family members of the critically ill patients. This may explain the unavailability of primary care nurses experienced by family members in $\mathrm{KNH}$.

\subsection{To Describe the Policies Guiding the Involvement of Families in Care of Critically Ill Patients}

According to the nurse managers there are no established policies that guide the involvement of families in critical care in $\mathrm{KNH}$. Lack of involvement policies was also reported in studies conducted in Bahrain and Malawi [11, 18]. Failure to have documented guiding policies on how what and when to involve families in care of critically ill patients leaves nurses and nurse managers to decide whether to do it or not which may disadvantage families depending on the decision the nurse makes and result in dissatisfaction of family members [19].

Most nurse managers agreed to the existence of a CCU visitation policy that is not open. One nurse manager felt a change that restricts who visits the patient to the next of kin only was important. These responses were unfortunate considering that families only get involved in patients care during visitation hours. The policy being a closed one is similar to several previous studies which include: a study conducted in the United Kingdom, the United States of America and also in Dutch ICUs whereby most hospitals had restrictive policies $[3,15,26]$. These findings are unfortunate considering that studies have already indicated the benefits and need for open visitation policies in critical care units. Studies thus need to be conducted on why nurses still prefer closed policies long after open policies have been proved as more beneficial to families and the patient.

\section{Conclusion and Recommendations}

Family members with patients admitted in KNH critical care units are involved in the care of their patients with an average satisfaction level of 6.5 out of 10 . However families were key point out the need for in-depth information provision by the primary care nurses to allow them plan financially and also decide what activities they can be involved in the patient care. Nurse managers on the other hand seemed to not be fully informed on guides to involvement of families in care of critically ill patients beyond general information provision as well as on the benefits of open visitation policies in ICUs with some even recommending more measures to restrict visitation further. $\mathrm{KNH}$ has a visitation policy which is closed but does not restrict who visit. However there is no policy guiding involvement of families in care of the patients.

Primary care nurses should engage family members of patients admitted in the $\mathrm{KNH}$ critical care unit since respondents felt this was lacking thus denying them in-depth information on their patients' condition, prognosis and care. A follow up study on perspectives of primary care nurses may help understand why primary care nurses don't involve families in general nursing care activities. This study also recommends that $\mathrm{KNH}$ establishes an involvement policy and ensures nurse managers in the facility are conversant with it to promote involvement.

\section{References}

[1] Santiago, C., Lazar, L., Jiang, D. and Burns, K., E., A. (2014) A survey of the attitudes and perceptions of multidisciplinary team members towards family presence at bedside rounds in the intensive care unit. Intensive and Critical Care Nursing, $30,13-21$.

[2] Kitto, S., Olding, M., McMillan, S., E., Reeves, S., Schmitt, M., H., and Puntillo, K. (2015) Patient and family involvement in adult critical and intensive care settings: a scoping review. Health Expectations. 1-20.

[3] Liu, V., Read, J., L., Scruth, E., and Cheng, E., (2013) Visitation policies and practices in US ICUs. http://ccforum.com/content/17/2/R71 (Accessed 18/12/2016).

[4] Gentry, S., McArthur, R., Millegan, J., Morris-White, E., Scott, S., and Williams, L. (2014) A Study to Evaluate the Needs of Family Members of Critically Ill Patients in the ICU. Nursing journal.

[5] Hinkle, J. L., and Fitzpatrick, E. (2011) Needs of American relatives of intensive care patients: Perceptions of relatives, physicians and nurses Intensive and Critical Care Nursing. Australian journal of advanced nursing. 27, $218-225$.

[6] Nelms, T., P. and Eggenberger, S., K. (2010). The Essence of the Family Critical Illness Experience and Nurse-Family Meetings Journal of Family Nursing. 16, 462-486.

[7] Bond, A. E., Draeger, C., R., L., Mandleco, B. and Donnelly, M., (2003) Needs of family members of patients with severe traumatic brain injury. Implications for evidence-based practice. Critical Care Nursing, 23, 63-72.

[8] Omari, F. (2012) Jordanian nurses' perceptions of their roles toward the families of hospitalized critically ill patients. Journal of Research in Nursing, 18, 669-680. 
[9] Ngui, M., L. (2006) Determination of families' needs of patients admitted in the intensive care unit (ICU) and the extent to which these needs are met as perceived by the family members and the ICU nurses at Kenyatta National Hospital. University of Nairobi College of Health Sciences Digital Repository 2006. (accessed 10/10/2016).

[10] Umani, K., O. (2014) A survey of ICU setups in the republic of Kenya. www.google.com (accessed on 3/11/2016).

[11] Fateel, E., E., and O'Neill, C., S. (2015) Family members' involvement in the care of critically ill patients in two intensive care units in an acute hospital in Bahrain: The experiences and perspectives of family members' and nurses' - A qualitative study. Clinical Nursing Studies, 4, 57-69.

[12] Zampieron, et al., 2008. Access to intensive care units: A survey in North-East Italy. Intensive Critical Care Nursing. 24(6), 366-374.

[13] Banh, M., A. (2013) A closer look at visitation hour policies in intensive care units. The Journal of Undergraduate Nursing Writing. vol 6, issue 1 (http://archie.kumc.edu/2271/237).

[14] Khaleghparast, S., Joolaee, S., Ghanbari, B., Maleki, M., Peyrovi, H. and Bahrani, N. (2015) A Review of Visiting Policies in Intensive Care Units. Global Journal of Health Science. 8(6): 267-276.

[15] Hunter, J. D., Goddard, C., Rothwell, M., Ketharaju, S., and Cooper H. (2010) A survey of intensive care unit visiting policies in the United Kingdom. Anaesthesia. 65(11), 11011105.

[16] El-Masri, M., M., and Fox-Wasylyshyn S., M., (2007) Nurses' roles with families: Perceptions of ICU nurses. Intensive and Critical Care Nursing 23, 1, 43-50.

[17] Tomnay, J. E., Kinrade, T., and Jackson, A, C. (2009) The psychosocial needs of families during critical illness: comparison of nurses' and family members' perspectives. Australian journal of advanced nursing. 27, 82-88.

[18] Gondwe, W. T. M., Bhengu, B. R. and Bultemeier, K. (2011) Challenges encountered by intensive care nurses in meeting patients' families' needs in Malawi. Africa Journal of Nursing and Midwifery, 13, 92-102.

[19] Matlakala, M. C. (2015) Sharing the critically ill patient's information with the family: Reflections and lessons learned. Journal of Nursing Education and Practice, 5, 115-119.

[20] Brysiewicz, P. and Bhengu B. R. (2010) The experiences of nurses in providing psychosocial support to families of critically ill trauma patients in intensive care units. A study in the Durban metropolitan area. South Africa Journal of Critical Care (SAJCC), 26, 42-51.

[21] Foster, M., Whitehead, L., and Maybee, P., (2015)The Parents', Hospitalized Child's, and Health Care Providers' Perceptions and Experiences of Family-Centered Care Within a Pediatric Critical Care Setting: A Synthesis of Quantitative Research. Journal of Family Nursing. 22, 6-73.

[22] Gallo, K., P., Hill, L., C., Hoagwood, K., E., and Olin, S., S., (2015) A Narrative Synthesis of the Components of and
Evidence for Patient- and Family-Centered Care. Clinical Pediatrics. 55, 333-346.

[23] Institute for Patient- and Family-Centered Care, (2010) Changing hospital "visiting" and policies and practices: supporting family presence and participation. http://www.ipfcc.org. Accessed December, 2016.

[24] Institute of Family Centered Care, (1992) Institute of Family Centered Care. (www.familycenteredcare.org/pdf/fcc_qa.pdf).

[25] Segaric, C., A., and Hall, W., A. (2014) Progressively Engaging: Constructing Nurse, Patient, and Family Relationships in Acute Care Settings. Journal of Family Nursing. 21, 35-56.

[26] Spreen, A. E., Marieke J. and Schuurmans, M. J. (2011) Visiting policies in the adult intensive care units: A complete survey of Dutch ICUs. Intensive and Critical Care Nursing. $27,27-30$

[27] Chaboyer, W. and Mitchell, M., L. (2010) Family Centred Care-A way to connect patients, families and nurses in critical care: A qualitative study using telephone interviews. Intensive and critical care nursing journal. 26 (3), 154-160.

[28] Vandall-Walker, V., and Clark, A., M. (2011) It Starts With Access! A Grounded Theory of Family Members Working to Get Through Critical Illness. Journal of Family Nursing. 17, 148-181.

[29] Rippin, A., S., Zimring, C., Samuels, O., and Denham, M., E., (2015) Finding a Middle Ground: Exploring the Impact of Patient- and Family-Centered Design on Nurse-Family Interactions in the Neuro ICU. Health Environments Research \& Design Journal, 9, 80-98.

[30] Kingsinger, V. (2015) "Family Centered Care in ICU Settings" Honors Theses. Paper

263.http://scholarworks.wmich.edu/honors theses. (accessed 18/11/2016).

[31] Azoulay, E., Pochard, F., Chevret, S., Lemaire, F., Mokhtari, M., Le Gall, J. R., Dhainaut, J. F. and Schlemmer, B. (2001) Meeting the needs of intensive care unit patient families. A multicenter study. American Journal of Respiratory And Critical Care Medicine, 163, 135-139.

[32] Kerr, E., M. (2000) “One Family’s Story: A Primer on Bowen Theory." The Bowen Center for the Study of the Family. $\mathrm{http}: / /$ www.thebowencenter.org.

[33] Ramos, F., J., Fumis, R., R., L., Azevedo, L., C., P., and Schettino, G. (2013) Perceptions of an open visitation policy by intensive care unit workers. Ann Intensive Care; 3: 34

[34] Meert, K., L., Clark, J., and Eggly, S. (2013) Family-centered care in the pediatric intensive care unit. Pediatric clinics of North America. 60(3), 761-772.

[35] Molter, N., C. (1979) Needs of relatives of critically ill patients: a descriptive study. Heart Lung. 8 (2), 332-339. [PubMed]. 